\title{
Os gêneros Sporobolus e Leptochloa (PoAceae-Chloridoideae) em Pernambuco, Brasil
}

\author{
Maria Bernadete Costa-e-Silva1 \& Jefferson Rodrigues Maciel ${ }^{2,3}$
}

\section{Resumo}

(Os gêneros Sporobolus e Leptochloa (Poaceae-Chloridoideae) em Pernambuco, Brasil) O presente trabalho é um levantamento taxonômico dos gêneros Sporobolus e Leptochloa, baseado em uma análise de material proveniente de coletas e depositados nos principais herbários de Pernambuco. Foi confirmada a ocorrência de quatro espécies do gênero Sporobolus e três do gênero Leptochloa. São apresentadas descrições dos táxons, chaves de identificação das espécies e informações sobre a ecologia e distribuição geográfica das espécies. Palavras chave: taxonomia, florística, gramíneas, Nordeste.

\section{Abstract}

(The genera Sporobolus and Leptochloa (Poaceae-Chloridoideae) in Pernambuco, Brazil) This paper is a taxonomic study of the genus Sporobolus and Leptochloa based in analysis of the material proceeding from collections and deposited in the main Pernambuco herbaria. It was confirmed the ocurrence of four species of Sporobolus and three of Leptochloa. Descriptions of the taxa, keys for the species and information about ecology and geographic distribution of the species are presented.

Key words: taxonomy, flora, grasses, Northeast.

\section{INTRODUÇÃo}

A família Poaceae está constituída por cerca de 40 tribos com 611 gêneros e aproximadamente 10.000 espécies (Watson \& Dallwitz 2000) amplamente distribuídas por todo o mundo. Para o Brasil são citadas 25 tribos, com cerca de 197 gêneros e 1368 espécies (Longhi-Wagner 2001).

São raros os trabalhos sobre a família no Nordeste, onde a mesma destaca-se tanto pelo grande número de espécies quanto por sua distribuição por todos os ecossistemas. Entre as principais pesquisas para esta região, estão Renvoize (1984) que cita para a Bahia cerca de 300 espécies reunidas em 19 tribos e Nascimento \& Renvoize (2001) que registram 157 espécies para o Piauí e Maranhão. Em Pernambuco, o estudo mais representativo foi realizado por Tenório (1968) que cita 80 espécies para o município de Recife.

Segundo Kissmann (1997) as gramíneas exercem grande influência sobre a humanidade, tendo uma vasta aplicação na alimentação humana, na produção de fibras, de açúcar e como forrageiras, além de protegerem o solo contra a erosão e possuírem algumas das mais agressivas espécies invasoras de cultura.

Para o nordeste brasileiro Renvoize (1984) ressalta a importância das Poaceae na possibilidade de utilização de pastos nativos na região. Na caatinga as Poaceae são predominantemente anuais, constituindo-se em uma boa fonte de alimentos para os animais na época das chuvas.

Poaceae foi estudada por inúmeros autores, entre eles Hitchcock (1936), que em sua primeira classificação apresentou-a um tanto artificial, separando-a em duas subfamílias: Festucoideae e Panicoideae. Mais recentemente Clayton \& Renvoize (1989) dividiram a família em nove subfamílias, entre as quais Chloridoideae de onde se destaca a tribo Eragrostideae com os gêneros Sporobolus e Leptochloa, aqui estudados.

Artigo recebido em 12/2004. Aceito para publicação em 10/2006.

${ }^{1}$ Herbário IPA da Empresa Pernambucana de Pesquisa Agropecuária. Av. Gal. San Martin 1371, Bongi, 50761-000, Recife - PE. Bolsista DCR - CNPq/FACEPE

${ }^{2}$ Bolsista PIBIC/CNPq/ FACEPE/IPA

${ }^{3}$ Autor para correspondência: jeffbio@pop.com.br 
Os táxons desta tribo apresentam folhas com lígula membranosa a ciliada, inflorescência com panícula típica ou de racemos unilaterais. Espiguetas 1-muitas floras, glumas persistindo após a queda do antécio, fruto apresentando algumas vezes o pericarpo livre.

Estes gêneros foram escolhidos como objetos deste trabalho por serem pouco estudados na região, por apresentarem relativa representatividade e pela necessidade de contribuir para o conhecimento da flora de Pernambuco, especialmente com a família Poaceae.

\section{Material e Métodos}

O estudo foi realizado com material depositado nos herbários IPA, UFP, HST e PEUFR. As descrições das espécies foram realizadas com base na análise morfológica das estruturas sob estereomicroscópio, sendo o estudo de cada táxon feito com o auxílio da literatura e por comparação com outros exemplares previamente identificados por especialistas. As ilustrações foram realizadas com o auxílio de uma câmara clara acoplada ao estereomicroscópio. Os dados sobre habitat e distribuição geográfica foram obtidos tanto das etiquetas das exsicatas, como da literatura especializada. A terminologia morfológica foi baseada em Longhi-Wagner (2001), e as siglas dos herbário foram citadas segundo Holmgren et al. (1990), com exceção do HST (Herbário Sergio Tavares), ainda não indexado.

\section{Resultados e Discussão}

Sporobolus R. Br. Prod. Fl. Nov. Holl.: 169. 1810.

Plantas anuais ou perenes, eretas ou decumbentes, cespitosas ou, menos freqüentemente, rizomatosas, prefoliação convoluta. Folhas concentradas na base do colmo com distribuição esparsa ao longo deste, ou densamente distribuídas ao longo do caule; lâmina foliar glabra ou pilosa, plana ou involuta; lígula ciliada a membranoso-ciliada. Panícula laxa, semicontraída a contraída, ramos alternos ou verticilados. Espiguetas unifloras, sem antécios rudimentares apicais; articulação da ráquila acima das glumas, estas persistem na inflorescência após a queda dos antécios maduros; gluma inferior bem menor que o lema ou atingindo metade do comprimento deste, a superior menor, igual, subigual ou ultrapassando o comprimento do lema; lema mútico, uninervado; pálea menor ou ultrapassando o comprimento do lema, 2-nervada; lodículas 2, reduzidas; estames 3. Fruto ovalado a arredondado, com as camadas mais externas do pericarpo se rompendo e liberando a semente envolta pelo endocarpo.

Sporobolus possui cerca de 100 espécies distribuídas nas regiões tropicais, subtropicais e temperadas do planeta (Burkart 1969; Torres 1970). No Brasil Sporobolus está representado por 30 espécies, com o centro de diversidade localizado na região central do país, onde há espécies relacionadas ao cerrado e campos rupestres (Boechat \& Longhi-Wagner 1995).

Por possuir apenas uma espigueta por antécio o gênero Sporobolus se aproxima de Muhlenbergia, do qual se diferencia por possuir o lema uninervado e mútico além da lígula ciliada ou membranoso-ciliada, enquanto que em Muhlenbergia o lema é 3-5 nervado com a nervura central prolongada em arista (Boechat \& LonghiWagner 1995). Um outro gênero que se aproxima de Sporobolus por possuir apenas uma espigueta por antécio é o gênero Pereilema, no entanto este gênero possui cerdas nas espiguetas o que não acontece em Sporobolus (Boechat et al. 2001).

Em Sporobolus o fruto é diferente das cariopses típicas dos outros gêneros de Poaceae. Neste gênero as camadas mais externas do pericarpo geralmente se rompem liberando a semente envolta pelo endocarpo. 


\section{Chave de identificação das espécies de Sporobolus em Pernambuco}

1. Plantas rizomatosas, folhas densamente distribuídas ao longo do colmo 4. S. virginicus

1'.Plantas cespitosas, folhas concentradas na base e esparsamente distribuídas ao longo do colmo.

2. . Gluma inferior atingindo metade do comprimento do lema e a superior igual ou subigual ao lema, face adaxial da lâmina foliar com longos pêlos submarginais .......2. S. pyramidatus

2'. Glumas menores que a metade do lema, face adaxial da lâmina foliar glabra

3. Lâmina involuta, panícula de semi-contraída a contraída 1. S. indicus

3’. Lâmina plana, panícula aberta 3. S. tenuissimus

1. Sporobolus indicus (L.) R. Br., Prodr. Fl. Nov. Holl. 170. $1810 . \quad$ Fig. 1 a-c; 3

Planta perene, ereta, cespitosa. Folhas concentradas principalmente na base, pouco distribuída ao longo do colmo; bainha glabra; lígula, $0,3-0,5 \mathrm{~mm}$ compr., membranoso-ciliada; lâmina ca. $43 \times 0,3-0,6 \mathrm{~cm}$, involuta, glabra. Panícula, 18-35,5 cm compr., semi-contraída a contraída; ramos inferiores da panícula 4,5$6,5 \mathrm{~cm}$ compr., os superiores medindo 1,4-2 $\mathrm{cm}$ compr. Espiguetas 1,5-2 ×0,01-0,03 cm, distribuídas desde a base dos ramos, mais concentradas nos ramos laterais; gluma inferior $0,3-0,5 \times 0,1-0,2 \mathrm{~mm}$, atingindo $1 / 3$ do lema, a superior $0,8-1 \times 0,1-0,2 \mathrm{~mm}$, igual ou subigual a metade do comprimento do lema; lema 1,6-2 ×0,5-0,7 mm; pálea 1,5-1,8×0,5$0,7 \mathrm{~mm}$. Cariopse ca. $1 \times 0,3 \mathrm{~mm}$, ovalada.

Sporobolus indicus é uma espécie com variações morfológicas. Segundo Boechat \& Longhi-Wagner (1995) existem duas variedades para esta espécie: $S$. indicus var. indicus e $S$. indicus var. pyramidalis (Beauv.) Veldk., enquanto Smith et al. (1982) citam como variedade $S$. indicus var. indicus e $S$. indicus var. exilis (Trin.) T. Koyama. Nos exemplares encontrados em Pernambuco as características analisadas não foram suficientes para justificar o uso das variedades.

Esta espécie cresce, sobretudo em ambientes ruderais ao longo dos caminhos e estradas, em solos rasos ou rochosos. As touceiras são muito enraizadas e apresentam uma coloração verde intensa, resistindo ao pisoteio do gado e à seca, sendo uma potencial forrageira nativa das regiões que sofrem com a seca no Nordeste. No entanto, segundo informações obtidas em Pickel (IPA-3120) esta planta hospeda carrapatos que atacam o gado, enquanto nova constitui-se em forrageira resistente, porém, quando velha torna-se lenhosa podendo machucar o gado.

Em Pernambuco esta espécie foi encontrada em regiões de mata úmida e cerrado do agreste, em campos altos e baixios formando maciços e pastos ora em solos arenosos, ora em locais úmidos à beira de açudes. Floresce todo o ano.

Material examinado: BRASIL. PERNAMBUCO: Cabo, Área do projeto Suape, estação D, 1.III.1978, fl.fr., D. Andrade-Lima \& Medeiros Costa 193 (IPA); Garanhuns, 18.VIII.1969, fl. e fr., E. C. Tenório 69-747 (IPA); Garanhuns, estrada para Santa Quitéria das Frexeiras, 18.VIII.1969, fl. e fr., E.C. Tenório 69-797 (PEUFR); Gravatá, nas encostas da Serra das Russas, 21.VIII.1969, fl. e fr., E. C. Tenório 69-841 (PEUFR); Recife, Cordeiro, 21.II.1959, fl. e fr., A. Sarmento 193 (PEUFR); Recife, Mata de Dois Irmãos, 1995, fl. e fr., R. Galindo 26 (IPA); São Lourenço da Mata, Mata do Toró, 1.IV.1928, fl. e fr., B. Pickel s.n. (IPA-3117); São Lourenço da Mata, Cercado, 29.II.1931, (fl.fr.), $B$. Pickel s.n. (IPA-3118); São Lourenço da Mata, Triângulo, 8.III.1935, fl. e fr., B. Pickel s.n. (IPA3119); São Lourenço da Mata, Estação Ecológica do Tapacurá, 12.XI.1977, fl. e fr., Pontual 1498 (PEUFR); XII.1923, fl. e fr., B. Pickel s.n. (IPA-3120).

2. Sporobolus pyramidatus (Lam.) Hitchc., U.S.D.A Misc. Publ. 243: 84. 1936.

Fig. 2 d-g; 3

Planta perene, ereta, cespitosa. Folhas esparsamente distribuídas ao longo do colmo, concentrando-se na base; bainhas foliares com pêlos longos concentrados no ápice, o restante da bainha glabra ou com cílios nas margens; 

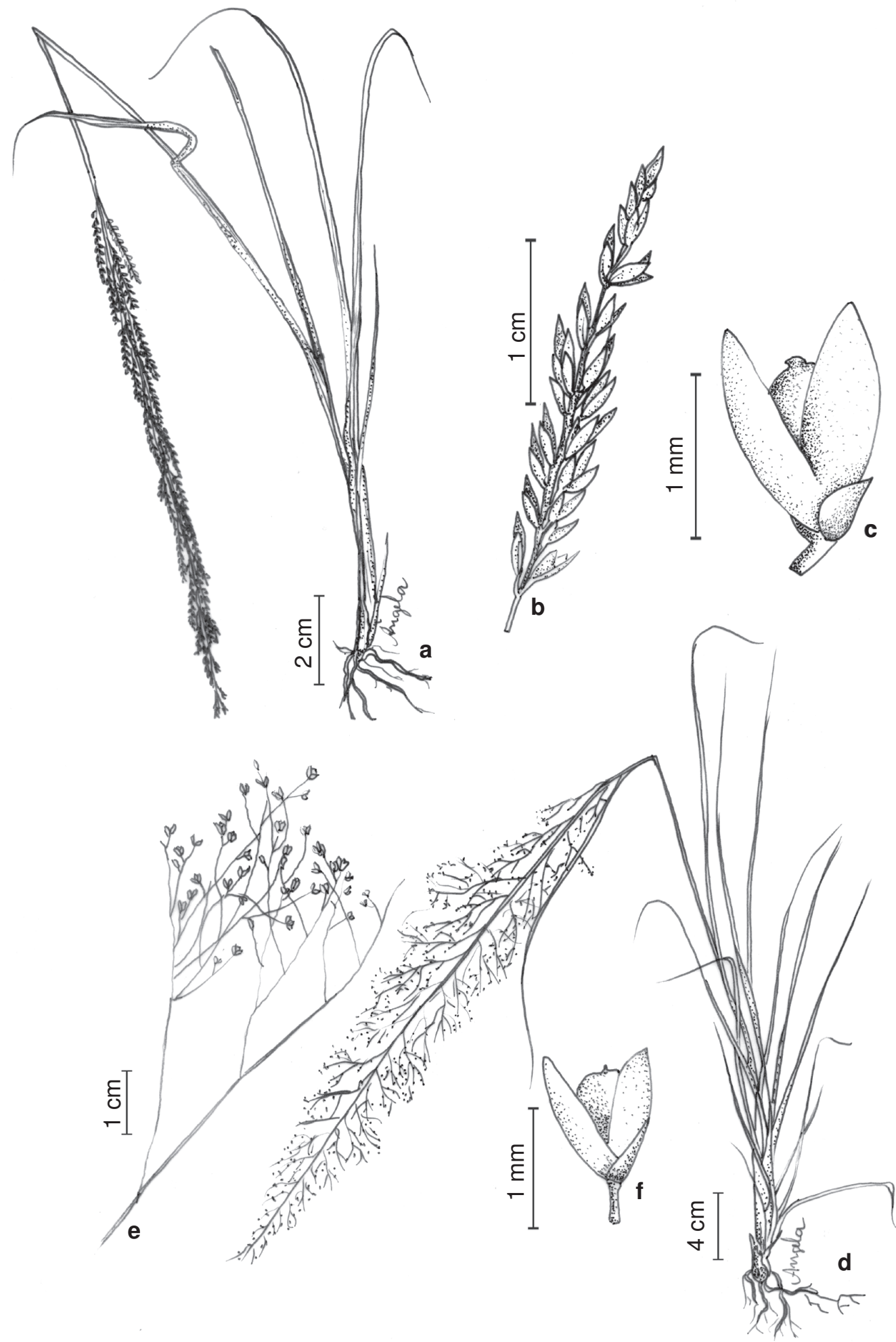

Figura 1 - Sporobolus indicus - a. hábito; b. detalhe do ramo da inflorescência; c. espigueta. Sporobolus tenuissimus d. hábito; e. detalhe do ramo da inflorescência; f. espigueta. 

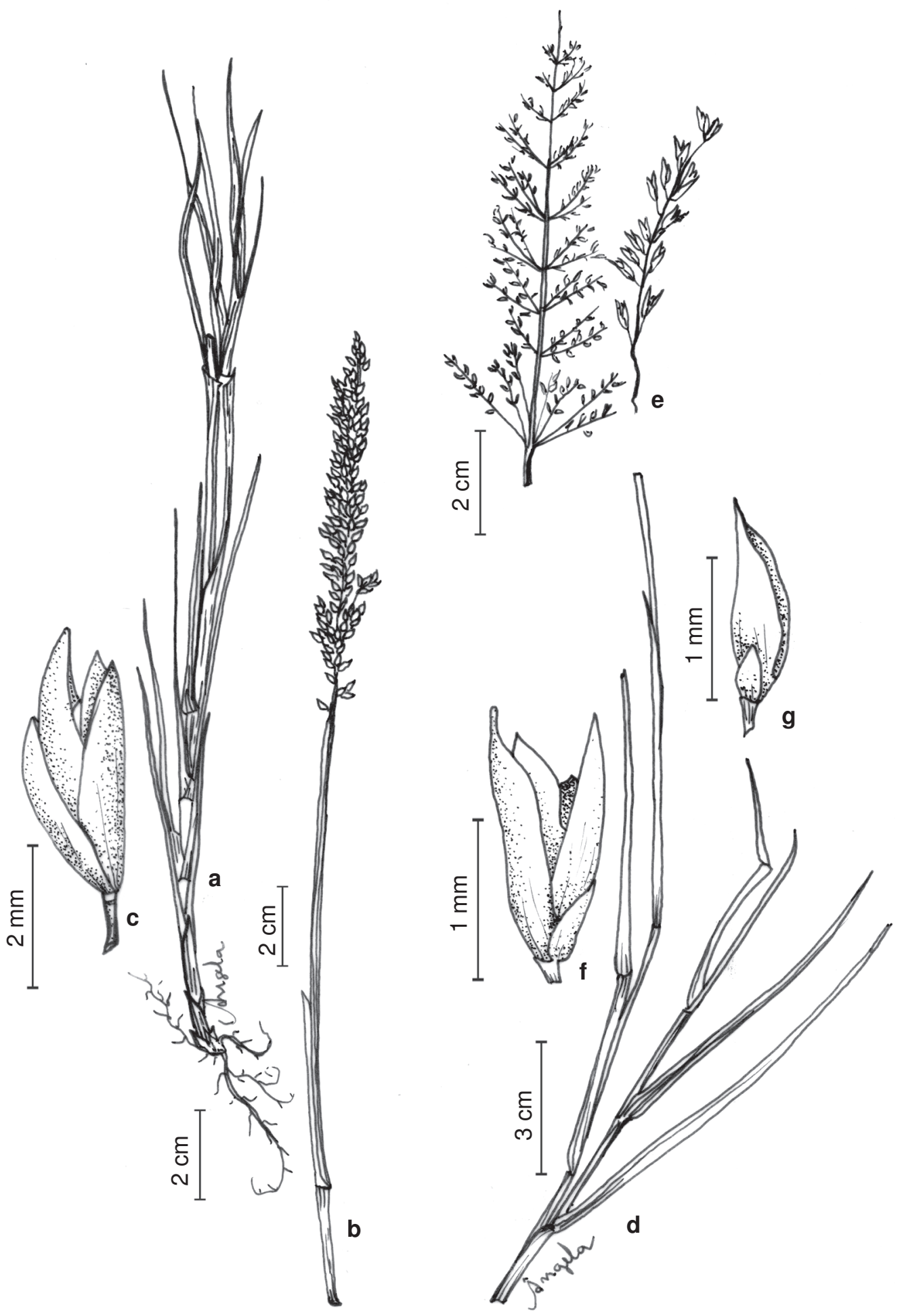

Figura 2 - Sporobolus virginicus - a. parte basal da planta; b. colmo florífero; c. espigueta. Sporobolus pyramidatus d. hábito; e. detalhe do ramo da inflorescência; f. espigueta; g. espigueta em vista da gluma inferior. 
lígula, 0,8-1 mm compr., ciliada, com longos pêlos nas laterais; lâmina foliar, 9-10,5 ×0,3$0,4 \mathrm{~cm}$, plana, face adaxial glabra, face abaxial com longos pêlos submarginais esparsamente distribuídos. Panícula, 9,8-14,3 cm compr., contraída quando jovem e aberta na maturidade; ramos da base da panícula 2,8$5,3 \mathrm{~cm}$ compr., ramos do ápice $0,4-1,7 \mathrm{~cm}$ compr. Espiguetas 1,7-2 × 0,2-0,5 mm, distribuídas até a metade nos ramos inferiores e até a base nos superiores; gluma inferior 0,3$0,6 \times 0,2-0,4 \mathrm{~mm}$, atingindo metade do tamanho do lema, gluma superior 1,5-1,9 $\times 0,3-0,5 \mathrm{~mm}$, maior que o lema; lema 1,2-1,8 $\times 0,3-0,5 \mathrm{~mm}$; pálea $1-1,6 \times 0,3-0,5 \mathrm{~mm}$. Cariopse $0,9-1 \times$ 0,1-0,4 mm, ovalada.

Esta espécie ocorre em Pernambuco nas regiões de agreste e sertão, crescendo sobre solos areno-argilosos. Floresce e frutifica todo o ano.

Sporobolus pyramidatus possui como característica típica o dimorfismo da panícula, no mesmo indivíduo as panículas jovens se apresentam contraídas e as maduras abertas, conferindo a planta um aspecto bastante diferente das outras espécies do gênero.

Material examinado: BRASIL. PERNAMBUCO: Brejo da Madre de Deus, encosta da Pedra do Cachorro, 19. IV. 1959, fl.e fr., D. Andrade-Lima 3347 (IPA); Floresta, próximo ao riacho Gravatá, 30.VIII.1958, fl. e fr., D. Andrade-Lima 3242 (IPA); Ibimirim, 1.II.2000, fl. e fr., L. M. C. Maia s.n. (IPA58712); Pombos, à margem da estrada, 6.VI.1934, fl. e fr., B. Pickel s.n. (IPA-3115); São José do Belmonte, 3.III.1961, fl. e fr., A. Sarmento 380 (IPA); Tacaimbó, à margem da rodovia, 11.IX.1969, fl. e fr., E. C. Tenório 69-988 (IPA).

Material adicional: BRASIL. PARAÍBA: Itabaiana, Alto do Pinheiro, VI.1928, fl. e fr., B. Pickel s.n. (IPA-3113).

\section{Sporobolus tenuissimus (Schrank)} Kuntze., Revis. Gen. Pl. 3(3): 369. 1898.

Fig. 1 d-f; 3

Planta anual ereta, cespitosa. Folhas esparsas distribuídas ao longo do colmo; bainha foliar glabra; lígula, 0,1-0,2 mm compr., ciliada; lâmina foliar 7,5-24×0,3-0,4 cm, plana, glabra. Panícula lanceolada, aberta com ramos delicados; ramos alternos, os inferiores 3,5-6 cm compr., os superiores 1-3 cm compr. Espiguetas $1 \times 0,1-0,3 \mathrm{~mm}$, distribuindo-se desde a base da panícula, com maior concentração no ápice; gluma inferior $0,1-0,3$ $\times 0,1 \mathrm{~mm}$, superior $0,4-0,6 \times 0,1-0,2 \mathrm{~mm}$, não atingindo metade do comprimento do lema; lema $1 \times 0,2-0,3 \mathrm{~mm}$; pálea $0,8-1 \times 0,2-0,3$ $\mathrm{mm}$. Cariopse $0,7-0,9 \times 0,2-0,3 \mathrm{~mm}$, oval a arredondada.

Sporobolus tenuissimus distribui-se em Pernambuco, sobretudo em regiões de mata úmida, mata seca e no agreste, porém pode ocorrer em campos e cerrado e em ambientes ruderais. Floresce todo o ano.

Boechat \& Longhi-Wagner (1995) comentam sobre a constante confusão que é feita entre Sporobolus tenuissimus e Eragrostis airoides Nees, devido as duas espécies possuírem inflorescências delicadas e laxifloras. Porém E. airoides se diferencia de $S$. tenuissimus por apresentar espiguetas com 1 a 3 antécios, cariopses sulcadas, tufo de pêlos na região ligular e bainhas foliares com pêlos hirsutos e submarginais, características não encontradas em $S$. tenuissimus.

Material examinado: BRASIL. PERNAMBUCO: Carpina, fazenda Limeira Grande, margem da estrada, 6.VI.1956, fl. e fr., M. Coelho s.n. (IPA-8510); Garanhuns, 18.VIII.1969, fl. e fr., E. C. Tenório 755, (IPA); Pesqueira, Salatil, VIII.1928, fl. e fr., B. Pickel s.n. (IPA-3122); Recife, Curado, 15.VIII.1958, fl. e fr., D. Andrade-Lima s.n. (PEUFR-1340); Recife, Mata de Dois Irmãos, 1995, fl. e fr., R. Galindo 34 (IPA); Recife, Parque do IPA, II.1936, fl., Vasconcelos Sobrinho s.n. (IPA-94, UFP); São Lourenço da Mata, IV.1958, fl. e fr., B. Pickel s.n. (IPA-3121); São Lourenço da Mata, VIII.1929, fl. e fr., B. Pickel s.n. (IPA-3123); Usina Olho D’ água, 4.X.1958, fl.fr., D. Andrade-Lima s.n. (PEUFR-1341).

4. Sporobolus virginicus (L.) Kunth, Revis. Gram. 1: 67. $1829 . \quad$ Fig. 2 a-c; 3

Planta perene, ereta ou decumbente, rizomatosa. Folhas densamente distribuídas ao longo do colmo; bainha glabra; lígula, 0,1 mm compr., ciliada; lâmina foliar 5,5-11 ×3-5 cm, face adaxial glabra, face abaxial com pêlos, 


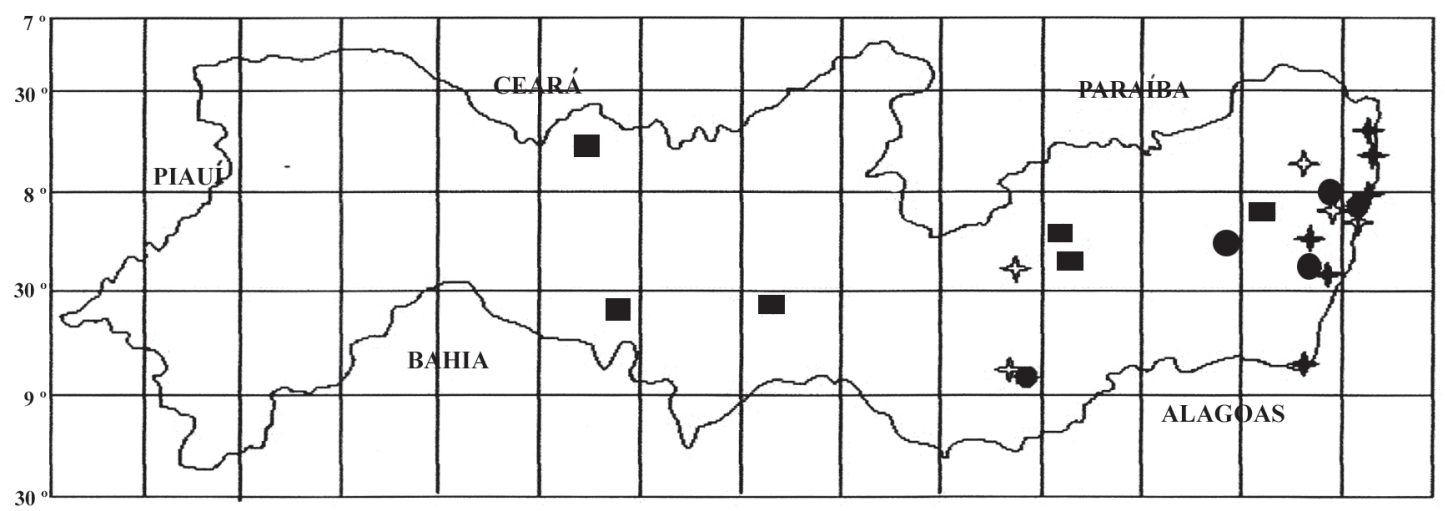

Figura 3 - Distribuição geográfica das espécies de Sporobolus ocorrentes em Pernambuco: Sporobolus indicus

S. pyramidatus $\square$; S. tenuissimus $\& ;$ S. virginicus

involuta. Panícula contraída, ramos alternos, os inferiores medindo 3-3,5 cm compr., os superiores $0,3-1,2 \mathrm{~cm}$ compr., com espiguetas distribuídas desde a base. Espiguetas, 2-2,5 $\times$ $0,6-0,9 \mathrm{~mm}$; gluma inferior, $1,5-2 \times 0,5-0,6$ $\mathrm{mm}$, atingindo metade do comprimento do lema; a superior, $2-2,3 \times 0,7-0,9 \mathrm{~mm}$, igual ou subigual ao comprimento do lema; lema 2-2,2 × 0,70,9 mm; pálea 2-2,2 $\times 0,6-0,7 \mathrm{~mm}$. Cariopse não vista.

Espécie típica das regiões litorâneas, onde se desenvolve em solos arenosos ou rochosos e em escarpas, nas quais pode formar populações densas ou pequenas colônias sobre blocos rochosos isolados. Floresce durante todo o ano. Material examinado: BRASIL. PERNAMBUCO: Cabo de Santo Agostinho, Baía de Suape/Rio Massangana, s.d., fl., D. Andrade-Lima \& Medeiros Costa 238 (IPA); Ipojuca, Porto de Galinhas, 26.IX.1988, fl., T. Duarte s.n. (UFP-7789); idem, praia do Cupe, 18.IV.1933, fl., B. Pickel s.n. (IPA-3124); Itapissuma, Coroa do Avião, 02.V.1992, fl., Marcos \& Rosineide (PEUFR-28768); Paulista, praia do Janga, 13.II.1971, fl., E. C. Tenório 1207 (PEUFR); Recife, Boa Viagem, 22.IV.1932, fl., B. Pickel s.n. (IPA-3125); São José da Coroa Grande, sítio Santo Antônio, 28.V.1971, fl., E. C. Tenório 1303 (PEUFR). Material adicional: BRASIL. PARAÍBA: Santa Rita, Ilha Tiriry, rio Paraíba, XI.1935, fl., P. Luetzelburg s.n. (IPA-22379). PIAUII. Ilha Grande de Santa Isabel, margem da estrada para Ilha da Batata, 13.V.1998, fl., M. S. B. Nascimento \& S. A. Renvoize s.n. (IPA59614). RIO GRANDE DO NORTE. Natal, dunas da Limpa, 10.IX.1953, fl., S. Tavares 342 (UFP).
Leptochloa P. Beauv., Ess. Agrost.: 71. 1812.

Plantas anuais ou perenes, eretas ou ascendentes, cespitosas ou, às vezes, com rizomas curtos; prefoliação convoluta. Folhas regularmente distribuídas ao longo do colmo; lâmina foliar plana ou involutas, glabras ou levemente pilosas na face inferior; lígula membranosa a membranoso-ciliada. Panícula de ramos unilaterais espiciformes ao longo do eixo principal alongado. Espiguetas 2-plurifloras, com ou sem antécio rudimentar apical; articulação da ráquila acima das glumas, estas persistindo após a queda do antécio maduro; glumas menores que o antécio, acuminadas a lanceoladas, múticas; lema mútico ou mais comumente com um múcron ou arístula entre os lobos, 3-nervado, ciliolado, lanceolado; páleas lanceoladas, subagudas ou lobadas, 2quilhadas, glabras ou cilioladas nas quilhas, persistentes. Estames 3. Cariopse típica, com sulco longitudinal ventral.

Leptochloa é um gênero composto de aproximadamente 40 espécies distribuídas nas regiões tropicais e subtemperadas do mundo (Clayton \& Renvoize 1989; Smith et al. 1982; Pohl \& Davidse 1994). No Brasil estima-se ocorrer de seis a oito espécies.

Leptochloa assemelha-se muito a Eragrostis por possuir uma espigueta lateralmente comprimida com vários antécios. panícula típica, laxa, aberta ou contraída. 


\section{Chave de identificação das espécies de Leptochloa em Pernambuco}

1. Lígula membranosa, $2-2,5 \mathrm{~mm}$; panícula contraída ...... 1. L. fascicularis

1'. Lígula membranoso-ciliada 0,9-4 mm, panícula semi-contraída a laxa

2. Glumas pouco desenvolvidas, a superior nunca atingindo metade do comprimento do antécio, 1,6-1,9 mm compr.; lema piloso nas nervuras dorsal e marginal 2. L. scabra

2'. Glumas bem desenvolvidas, a superior atingindo metade do comprimento do antécio, 2,12,4 mm compr.; lema com tricomas subdensos e adpressos na superfície..... 3. L. virgata

1. Leptochloa fascicularis (Lam.) A. Gray, Man. 588. 1848. Fig. 4 a-c; 5

Planta perene, cespitosa. Lâmina foliar 8,7$19 \times 0,4-0,8 \mathrm{~cm}$, plana, glabra; colo glabro; lígula, 2-2,5 mm compr., membranosa; bainha glabra. Panícula 12,6-26 cm, contraída; ramos, 2,3-7 cm compr., alternos. Espigueta 7,1-8,5 mm compr., 7-9 floras, distribuídas desde a base; antécios laxamente imbricados, antécio rudimentar presente no ápice da espigueta; glumas menores que a metade do comprimento do antécio, uninervadas, múticas, paleácea, agudas a lanceoladas, gluma inferior 1,1-2×0,3-0,8 mm, a superior $2-3 \times 0,8-1 \mathrm{~mm}$; lema lanceolado, curtamente aristulado, piloso nas margens inferiores; pálea lanceolada, curtamente aristulada, pilosa nas margens inferiores, fortemente imbricadas. Cariopse não vista.

Ocupa solos úmidos ou encharcados e em Pernambuco foi encontrada desde a mata úmida até a caatinga.

Material examinado: BRASIL. PERNAMBUCO: Águas Belas, entrada Buíque-Águas Belas, 18.IX.1969, fl. e fr., E. C. Tenório 1092 (IPA); Belém de São Francisco, fazenda Manga de Baixo, 21.VII.1967, fl. e fr., E. C. Tenório 335 (IPA); Buíque, 13.IX.1969, fl. e fr., E. C. Tenório 1056 (IPA); idem, 13.IX.1969, fl. e fr., E. C. Tenório 1061 (PEUFR); Carrapotós, 22.XI.1936, fl. e fr., B. Pickel s.n. (IPA1184); Garanhuns, fazenda do Notaro, XI.1929, fl.fr., B. Pickel s.n. (IPA-3174); Gravatá, 21.VIII.1969, fl. e fr., E. C. Tenório 851 (IPA); idem, 21.VIII.1969, fl. e fr., E. C. Tenório 862 (PEUFR); Iati, estrada Iati Bom Conselho, 29.VIII.1969, fl. e fr., E. C. Tenório 966 (IPA); Iati, manchas alagadas, 28.VIII.1969, fl. e fr., E. C. Tenório 940 (PEUFR); Pombos, 1.I.1933, fl. e fr., B. Pickel s.n. (IPA-3180); São Caetano, fazenda Bonfim, 24.IV.1966, fl.fr., E. C. Tenório 112 (IPA); São Lourenço da Mata, IX.1928, fl.fr., $B$. Pickel s.n. (IPA-3179); Triunfo, 12.IX.969, fl. e fr., E. C. Tenório 1012 (PEUFR).
2. Leptochloa scabra Nees, Agost. Bras. 435. 1829.

Fig. 4 g-i; 5

Planta anual, cespitosa. Lâmina foliar 20$48 \times 0,3-0,7 \mathrm{~cm}$, plana, glabra; colo glabro; lígula $4 \mathrm{~mm}$ compr., membranoso-ciliada; bainha glabra. Panícula 19-30,4 cm compr., laxa a semi-contraída; ramos 4,5-9,3 cm compr., alternos, flexíveis, densifloros, com espiguetas distribuídas desde a base. Espiguetas 3-4,2 mm compr., 3-4 floras; glumas paleáceas, não atingindo a metade do comprimento do antécio, múticas, lanceoladas, uninervadas, a inferior $1-1,5 \times 0,2-0,5 \mathrm{~mm}$, escamiforme, a superior 1,6-1,9 $\times 0,4-0,7 \mathrm{~mm}$; lema lanceolado, mútico a curtamente mucronado, piloso nas nervuras dorsal e marginal; pálea lanceolada, mútica a curtamente mucronada, 2-lobada, sem arístula entre os lobos, pilosa nas margens dorsal e marginal. Cariopse não vista.

Encontrada em Pernambuco em regiões de restinga e na mata. Também apresenta uma tendência para ocupar locais úmidos. Floresce de junho a dezembro.

Material examinado: BRASIL. PERNAMBUCO: Ilha de Itamaracá, 18.II.1969, fl.fr., E. C. Tenório 663 (PEUFR); Usina Mussurepe, 25.IX.1935, fl., s.col. (IPA-3181); Recife, Curado, 15.VIII.1958, fl., D. Andrade-Lima s.n. (PEUFR-1438); São Lourenço da Mata, 25.V.1936, fl., E. B. C. Filho s.n. (IPA-1186).

3. Leptochloa virgata (L.) P. Beauv., Ess. Nouv. Arost. 71, 166.1812. Fig. 3 d-f; 5

Planta perene, cespitosa. Lâmina foliar, $15-19,5 \times 0,5-1,2 \mathrm{~cm}$, plana, glabra ou levemente pilosa na face inferior, colo glabro; lígula, 0,9-1,3 mm compr., membranoso-ciliada; bainha glabra. Panícula, 10-19,6 cm compr., laxa; ramos, 6-16,5 cm compr., alternos, subdensifloros, semi-rígidos ou eretos. 

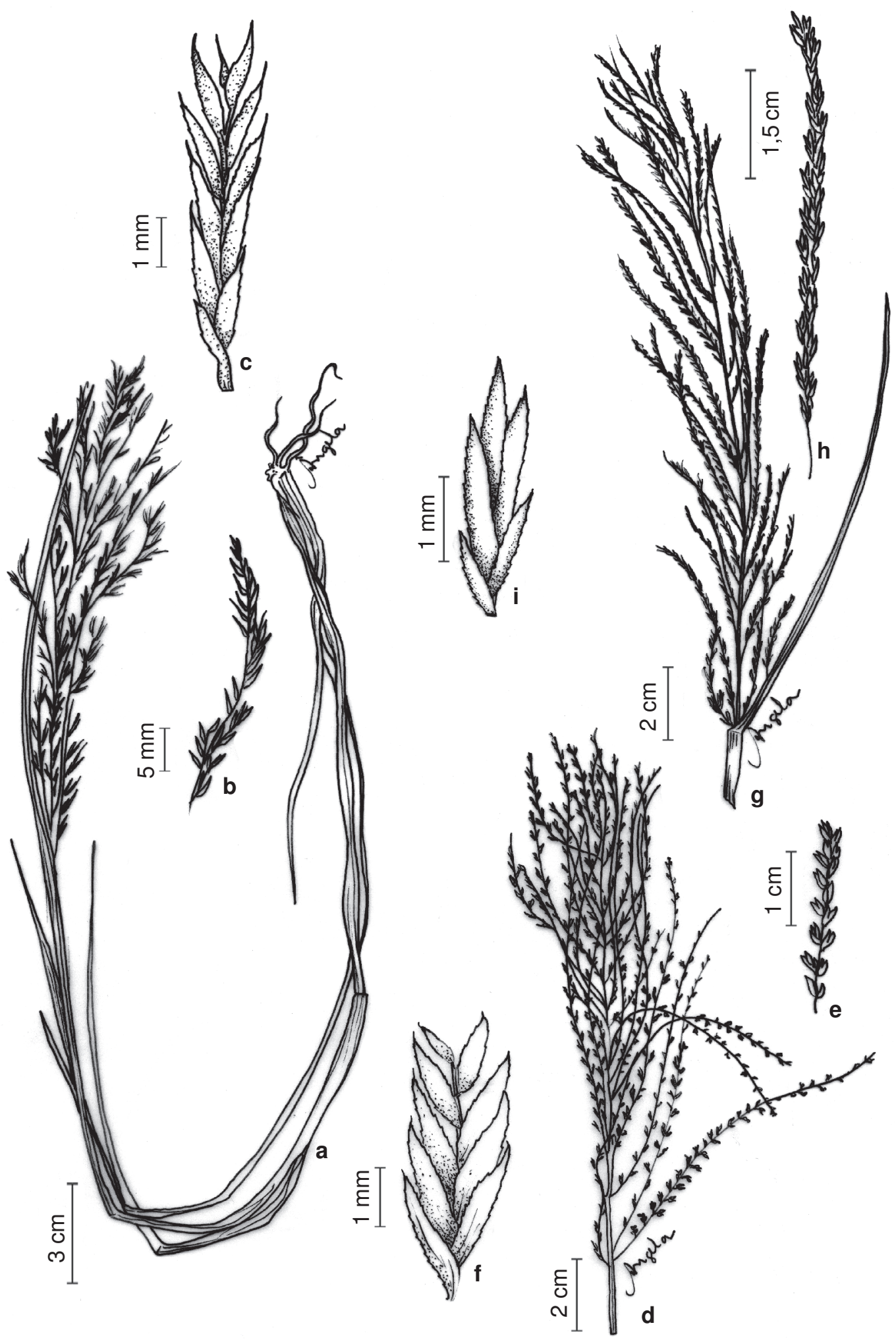

Figura 4 - Leptochloa fascicularis - a. hábito; b. detalhe do ramo da inflorescência; c. espigueta. Leptochloa virgata d. inflorescência; e. detalhe do ramo da inflorescência; f. espigueta. Leptochloa scabra - g. Inflorescência; h. detalhe do ramo da inflorescência; i. espigueta. 
Espigueta 2,6-3,2 mm compr., 4-5 floras, com antécio rudimentar apical; antécios fortemente imbricados; glumas bem desenvolvidas, lanceoladas, agudas ou acuminadas, a inferior não escamiforme, $1,5-1,8 \times 0,2-0,3 \mathrm{~mm}$, a superior $2,1-2,4 \times 0,2-0,4 \mathrm{~mm}$, atingindo metade do comprimento do antécio; lema mútico ou aristulado com tricomas subdensos e adpressos na superfície; pálea lanceolada, fortemente imbricada, aguda, mútica, 2-lobada. Cariopse não vista.

Leptochloa virgata é uma planta exótica originária do Velho Mundo e vastamente dispersa no Brasil como planta ruderal crescendo em beira de caminhos ou em terrenos cultivados, é também comum em margens de florestas ou áreas perturbadas.

Em Pernambuco ocorre na mata, sendo encontrada em locais úmidos à beira de rios ou em valas. Floresce quase todo o ano. Kissman (1997) cita esta espécie como infestante.

Material examinado: BRASIL. PERNAMBUCO: Recife, Curado, 2.VIII.1958, fl., D. Andrade-Lima (PEUFR-1439); São Lourenço da Mata, 20.II.1936, fl., B. Pickel s.n. (IPA-3185); idem, VI.1928, fl., B. Pickel s.n. (IPA-3183); idem, VI.1924, fl., B. Pickel s.n. (IPA-3182).

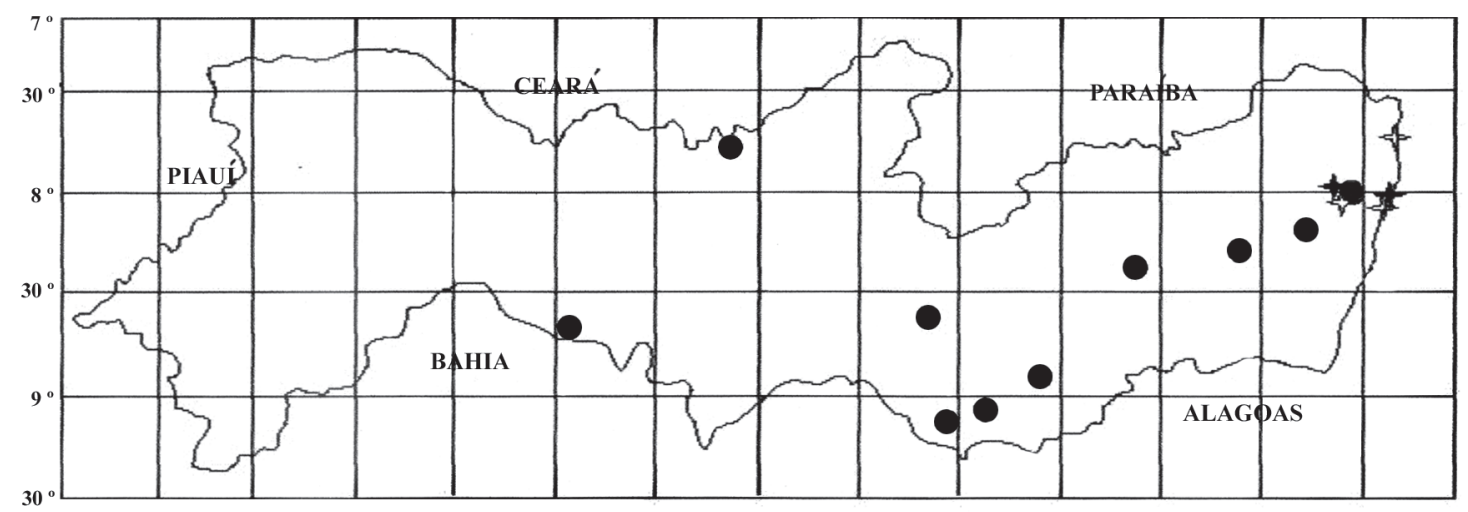

Figura 5 - Distribuição geográfica das espécies de Leptochloa ocorrentes em Pernambuco: Leptochloa fascicularis

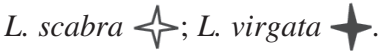

\section{REFERÊNCIAS BIBLIOGRÁFICAS}

Boechat, S. C. \& Longhi-Wagner, H. M. 1995.

O gênero Sporobolus (Poaceae: Chloridoideae) no Brasil. Acta Botânica Brasilica 9(1): 21-85.

Boechat, S. C.; Guglieri, A. \& Longhi-Wagner, H. M. 2001. Tribo Eragrostideae Poaceae In: Longhi-Wagner, H. M.; Bittrich, V.; Wanderley, M. G. L. \& Shepherd, G. J. (eds.). Flora Fanerogâmica do Estado de São Paulo. Vol. 1. Hucitec, São Paulo. Pp. 61-84.

Burkart, A. 1969. Flora Ilustrada de Entre Rios (Argentina): Gramíneas. INTA, Buenos Aires, 2: 226-230 (Coleción Científica. 6).

Clayton, W. D. \& Renvoize, S. A. 1989. Genera Graminum - Grasses of de World.
Kew Bulletin Additional series XIII, London, 389p.

Hitchcock, A. S. 1936. Manual of the grasses of the West Indies. U.S.D.A. Miscellaneous Publication, Washigton, n. 200.

Holmgren, P. K.; Holmgren, N. H. \& Barnett, L. 1990. Index herbariorum. Part 1: The Herbaria of the world. 8ed. New York Botanical Garden, New York, 693p.

Kissman, K. G. 1997. Plantas Infestantes e Nocivas. Vol.1. BASF, São Paulo, 826p.

Longhi-Wagner, H. M. 2001. Poaceae In: Longhi-Wagner, H. M.; Bittrich, V.; Wanderley, M. G. L. \& Shepherd, G. J. (eds.). Flora Fanerogâmica do Estado de São Paulo. Hucitec, São Paulo, 294p. 
Nascimento, M. P. S. C. B. \& Renvoize, S. A. 2001. Gramíneas forrageiras naturais e cultivadas na região meio-norte. Embrapa Meio-Norte, Teresina, 196p.

Pohl, R. \& Davidse, G. 1994. Leptochloa. In: Davidse, G.; Sousa, S. \& Chater, A. (eds.). Flora Mesoamericana 6: 260-261.

Renvoize, S. A. 1984. The grasses of Bahia. Royal Botanic Gardens, Kew, 301p.

Smith, L. B.; Wassahausen, D. C. \& Klein, R. M. 1982. Gramíneas: Flora Ilustrada Catarinensis. I. 440p.
Tenório, E. C. 1968. Gramíneas do Município do Recife. Boletim Técnico do Instituto de Pesquisas Agropecuárias 36: 1-99.

Torres, M. A. Sporobolus. In: Cabrera, A. L. 1970. (ed.). Flora de la Provincia de Buenos Aires; Gramíneas. INTA, Buenos Aires, 2: 374-82. (Coleción Científica. 4)

Watson, L. \& Dallwitz, M. J. 2000. The Families of Flowering Plants: Descriptions, Illustrations, indentification and Information Retrieval. Version: 14th December. http:/ /biodiversity.uno.edu/delta 